\title{
Assessing the Implementation of Managerial Reforms in the Government of Catalonia: The Development of Professional Public Management
}

Francisco Longo and Marc Esteve

Postal Address:

ESADE, Av. Pedralbes, 60-62. E-08034 Barcelona, Spain.

Francisco Longo is professor of human resources and public management and the Director of the Institute of Public Governance and Management at ESADE Business School - Ramon Llull University.

Email contact: f.longo@esade.edu

Marc Esteve is a PhD Candidate in Management Sciences at ESADE Business School and he is currently a visiting researcher at Cardiff University.

Email Contact: marc.esteve1@ esade.edu 


\title{
ASSESSING THE IMPLEMENTATION OF MANAGERIAL REFORMS IN THE GOVERNMENT OF CATALONIA
}

\begin{abstract}
This paper examines the degree of development of managerial reforms in the Government of Catalonia. Results show a very different scenario than expected. Reforms aimed to provide public administrations with more managerial oriented frameworks are far from achieving embeddedness in Catalan administrations, particularly in areas like accountability and incentives systems.
\end{abstract}

\section{Introduction}

In the early 1980s, the management of public administration in most OECD countries underwent significant reform in a process termed new public management (Aucoin, 1990; Barzelay, 2000, 1999; Hood, 1991; OECD, 2005). This public management reform was characterized by a rapprochement with business management methods (Dunleavy and Hood, 1994) focusing on "the ideas of contestability, user choice, transparency and close concentration on incentive structures" (Hood, 1991). The new approach was quickly introduced into public administration research agendas and has served as a framework for a large number of studies over the last two decades (e.g. Broadbent and Laughlin, 1997; Sprigings, 2002). Recently, however, the assumptions on which the restructuring of public management was based have been increasingly called into question. An example of this change is the revision of the new public management proverbs developed by Meier and O'Toole (2009). These authors question 
the extent to which contracting out, bureaucracy declination, organizational flexibility and other new public management practices have led to performance improvements.

Reforms in public administration are evident not only in formal processes, but also in an evolution toward a different set of values and an increase in the legitimacy of public servants as managers of public resources (Bresser-Pereira, 2004). There are a number of different proposals and approaches to developing public administration, but the underlying questions are always the same: How should management be understood in public administration? What is the role of public managers? How should public organizations be managed? Longo (2006) has developed the concept of "professional public management," which is considered a valid framework for measuring the development of public administration reforms.

The concept of Professional Public Management (PPM) refers to the organizational space occupied by those roles that have executive responsibilities within public administrations, and is aimed at differentiating politicians from public managers (see Longo, 2004). In recent years, the number of public managers and the degree of professionalization of public organizations has increased. Moreover, the role of PPM in political-administrative systems has been consolidated. In a context where the boundaries between politics and management are not always clearly drawn (Pollit and Bouckaert, 2000), the PPM sets out guidelines for orchestrating the processes of implementing policy and providing public services.

This article takes the position that a more developed public management culture is needed; however, we question the degree to which such reforms are actually taking place in public administration. This is developed by assessing the extent to which public organizations in Catalonia have adopted the PPM culture. The analysis provided in this study should be of interest to public managers and academics concerned with public 
administration reform. Specifically, this is of high interest to those countries where the boundaries between political figures and managers coming from administrative careers in public service are blurred, such as in Spain, France or Italy (see Barzelay and Gallego, 2010).

In the present paper, we intent to develop what Barzelay and Thomson have acknowledged as deliberative argumentation (see Barzelay and Thompson, 2010). As these authors explain, "deliberative argumentation consists of several elements: careful observation, thick description, normative reasoning about what constitutes a good outcome, and evaluation, reflecting different beliefs, values, and attitudes" (2010, pp 295). In a nutshell, then, the concept of deliberative argumentation aims researchers to formalize valid general advice out of specific practical evidence, such as a case study, that can be effectively implemented again in specific situations. In order to do so, the paper is organized as follows. First, we define a framework for assessing PPM, focusing on variables central to the study. Second, we apply the PPM framework to public administrations in Catalonia, at both regional and local levels. The third section presents the results of the study. Finally, we draw conclusions to generalize our findings and propose guidelines for further study.

\section{The PPM Framework}

In an attempt to frame the theoretical construct of PPM, Longo (2006) has developed a framework (see Figure 1) that defines important concepts and outlines links and interrelations between the different variables associated with institutional development under PPM. 
Figure 1. Analytical Framework of the Institutional Development of the Professional Public Management

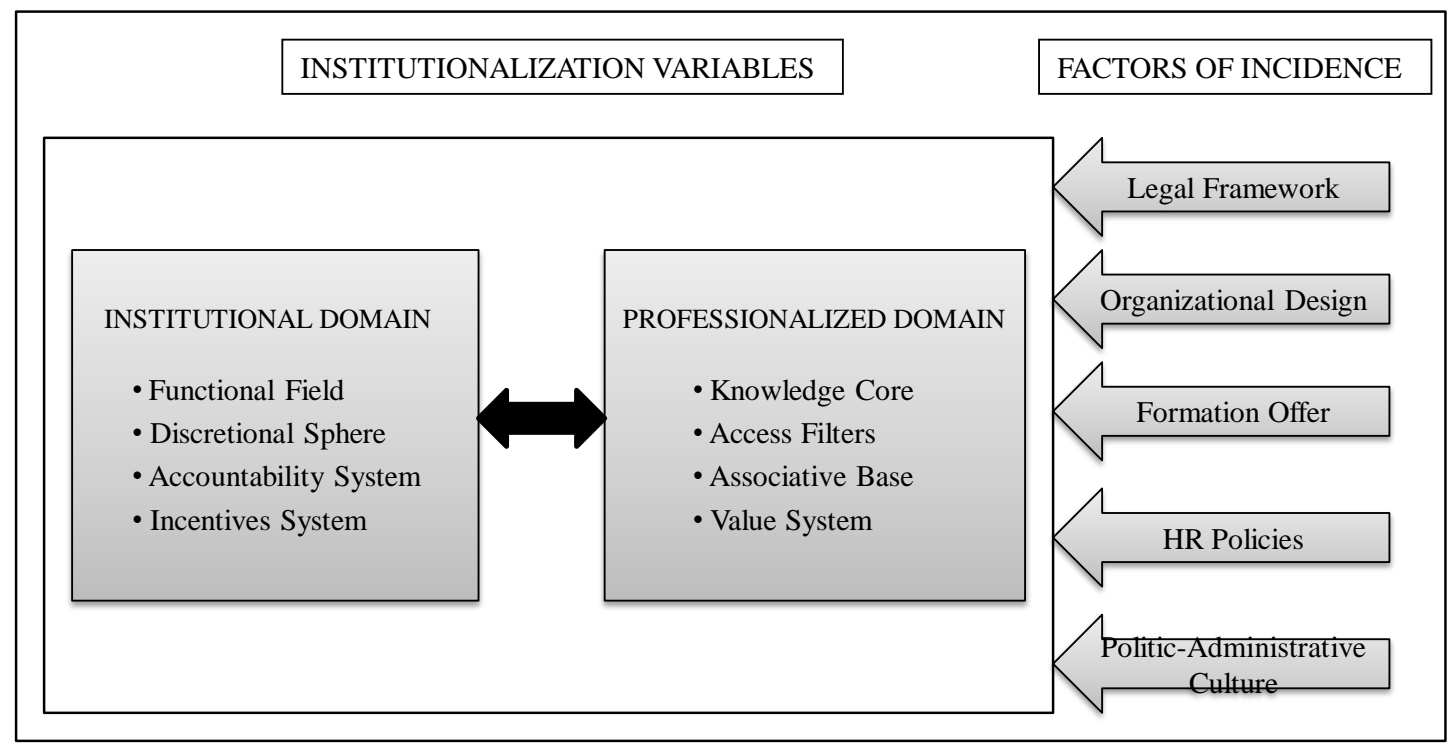

Source: Longo, 2006.

Figure 1 presents two major categories of institutionalization variables related to the demand and supply sides of PPM. The first category of variables is related to the configuration of an institutional domain in which PPM can be implemented and successfully developed. The second category of variables is related to the professionalized domain, which is understood as having the capacity to produce PPM to meet the needs of the organization. The right side of the figure shows factors that influence the activation and development of this second category of variables. The matriarchal structure of the figure is the expression of the transversal influences that these factors practice on the institutionalization variables. Since the unit of analysis in the present study is the public organization, we focus on the four variables present in the institutional domain, leaving aside the professionalized domain.

- Functional Field, for strong PPM, every public organization needs to have a specific functional field differentiated from the political direction of the institution. This delimitation is best achieved when the director of the 
organization has advanced managerial capabilities and a moderated political role. Thus, professional criteria should be prioritized over the historically valuable qualities of trust and loyalty in the recruitment of managers.

- Discretional Sphere, it is not possible to manage an organization without being able to consider available options and make decisions. Therefore, the extension of the activity domain for public managers and an increase in the autonomy of management are assumed to be the two main drivers of the discretional sphere. PPM gives public managers the power to implement public services by allowing them to make decisions in central management areas, such as the development of organizational strategy and the management of financial and human resources.

- Accountability System, by giving public managers more power, autonomy, and room to manoeuvre, a strong accountability system can be developed. An accountability system allows for the control of professional public managers through performance evaluations. As Gray and Hood (2007, p. 89) suggest, "the huge amounts of public service activity and expenditure require for effective governance a valid, reliable and timely method of measurement." The core of public accountability should shift, therefore, from a simple assessment of the regularity and legality of procedures to a system that allows for the evaluation of managerial performance. The creation of such an accountability system need not be driven by the neo-Taylorist perspective, which seeks the simplicity of the confrontation of a goal with the result of an indicator; rather, accountability systems should be able to manage the complexity of implementing public policy. As Bardach (1998) notes, the process of measuring and evaluating results is not by itself the solution to all problems of accountability. Measurements of success 
should be designed not only for post-hoc evaluation but also as an important tool for developing a sustained dialog about ongoing performance (Dilulio, 1994).

- Incentives System, finally, the PPM framework also proposes that a regime of consequences related to performance evaluation is essential. Without this regime, any control system can be expected to become less effective over time. As Longo (2006, p. 74) states: "The performance responsibilization is coherent with an environment with entrepreneurial public managers, compromised with the improvement of the results." A balance must be achieved between positive incentives (for example, higher wages) and more negative ones (linking job position to performance).

This article explores the degree of development of each of the four PPM variables discussed here and evaluates empirical evidence about the degree of development of PPM in the autonomous and local administration of Catalonia.

\section{Research Methods}

Individual semi-structured interviews, as well as focus group techniques, were used to collect the data for this study. As part of a larger project, individual and group interviews were conducted with 20 experienced public managers from Catalan public administrations in 2008.

The public managers who participated in the study were chosen according to two main criteria. First, the research team had to consider them experts in Catalan public administration, due to their experience, knowledge, academic background, and role inside their organizations. Hesse-Biber and Leavy (2006) argue that it is fundamental to ensure that people included in a study sample have specific knowledge, experience, or information about the topic studied. Second, we sought to represent the four main types 
of public administration found in Catalonia. Thus, our sample was composed of managers from:

- Direct autonomous government, managers of public organizations from the Generalitat de Catalunya (government of Catalonia). They operate centrally and are divided into different departments (health, justice, interior, etc.).

- Indirect autonomous government, managers of public organizations from the Generalitat de Catalunya who have some decentralized autonomy (autonomous entities, public companies, public entities that operate under private law, etc.).

- Direct local government, managers from the Catalan councils who operate within the central administrative structure of local government.

- Indirect local government, managers from the Catalan councils who have some decentralized autonomy (autonomous entities, public companies, public entities that operate under private law, etc.).

Before they were included in the sample, each manager was contacted by phone, provided with an overview of the research project, and asked to agree to participate. From the final group of 20 managers, 15 were interviewed on an individual basis and five participated in a focus-group session, within which the four different organizational types were represented.

A focus group allows researchers to collect information that emerges from group interactions; the researcher acts as a guide to ensure that the discussion remains focused on the research topic (Fern, 2001; Frey and Fontana, 1991; Morgan, 1993, 1996). In this study, the focus group session lasted 130 minutes. We used a focus study to complement individual interviews for two reasons. First, some of the managers in our sample were willing to participate in a group session, which was especially interesting for us because they represented the four types of organizations under study. Second, we 
are convinced of the value that this research technique can bring to researchers; in fact, some authors (see, among others, Fern, 2001; Morgan, 1993; Morgan, 1996) have acknowledged its value as a data-gathering instrument for social science studies.

The 15 individual interviews had an average duration of 70 minutes. All interviews were recorded and later transcribed and coded by the researchers. We also considered the researchers' notes taken during each session. The semi structured interviews where formed of 22 questions. The next section provides an analysis of the data.

\section{Results}

In this article we explore perceptions among Catalan public managers about the existence of an institutional space in which PPM can exist and be developed. We will present the results of the individual interviews and the focus group in two parts, according to the two main objectives of the research. The first related to the implementation of the four variables associated with the institutional domain of PPM, and their degree of development in autonomous and local Catalan administrations. The second was to assess the perceptions of public managers about the domain (regional or local) and the functional schemes (direct or decentralized) in which PPM has been successfully implemented, and in which the four institutional variables take on desirable values.

\section{PPM development according to the conceptual variable of institutionalization}

When looking at how public managers perceive the degree of PPM development in their organizations, the managers in our sample agreed that overall the degree was still insufficient and unsatisfactory. Moreover, when the values of the four variables were 
requested, the functional field and discretional sphere were seen as being more developed; the lowest levels were given to the accountability and incentives systems. Thus, from the perspective of the public managers interviewed, it can be extrapolated that Catalan public organizations have not yet developed effective accountability and incentive systems. Public managers operate without a framework that rewards success and penalizes failure.

The managers interviewed had forceful opinions about the accountability system: "We have an endemic accountability problem," said one manager who emphasized that this subject has not yet been developed in Catalan public administrations. "It is a disaster," claimed another director, explaining that the poor accountability system is a consequence of the lack of a culture of organizational and managerial evaluation. Another interviewee recognized that some isolated initiatives have been carried on in order to promote better control, but said, "We have an accountability system that is misleading - a front for the enormous deficiencies that really exist" that hides enormous deficiencies in this field. "No one has evaluated me ever," said one public manager.

It is worth noting that some managers blame themselves for the lack of accountability. They argue that managers have the responsibility to define their objectives, accomplishment indicators and expected results. Without responsible managers who acknowledge their own role in the game, it is very difficult to develop accountability measures, as some of the managers interviewed pointed out.

None of the interviewees denied the importance of having more developed accountability systems. Those who were more critical explained that failures to develop effective accountability systems resulted from the technical difficulty of designing an effective scheme of performance and evaluation measures; from "evil effects," such as discouragement among employees with managerial responsibilities or the political 
variability that affects strategic objectives; and from the size of their organizations and the very nature of the public services they offer.

There was agreement among public managers that there is a lack of rigorous accountability schemes for public managers, but that there are mechanisms for evaluating public policy objectives. The managers claimed, therefore, that systems should be developed to link those objectives to managerial performance. On the other hand, one manager said that much work still needed to be done in evaluating public policies: "I do not see any unity between the evaluation of policies and the professionalization of public management."

One manager stated: "If there are no objectives, there cannot be an incentives system." He stressed that the two questions must be related and that, even if it is true that the law foresees a "productivity complement," it is also true is that "there is not a culture of objectives and evaluation."

There is a lack of agreement on the convenience of establishing formulas that acknowledge a manager's achievements. For example, one manager said, "It is not easy (and I am not sure that it has to be done) to establish a variable payment linked to accomplishment. This can be done in the private sector, but it is more complicated in the public sector ... We must have incentives. However, this point has to be carefully analyzed because of the lack of a well-developed evaluation system. What's more, perverse effects could be generated."

Among the more optimistic respondents, one manager declared that there are some informal incentives (the chance to attend conferences and attain masters' degrees, for example), but they are not regulated, nor provided systematically. A participant in the focus group argued, "I do not know any incentive system. If it is not formalized, then it is not a system (by definition)." 
The functional field and the discretional sphere were rated more positively, but different opinions held. Public managers pointed out that their organizations contain several positions for which managerial techniques are fundamental. These positions require a director with a more managerial than political profile. Such positions are appointed directly by politicians and not by formal selection mechanisms that ensure the competitiveness of the process. In one of the interviews, it was said that the political affiliation of candidates and their relationship with the party counted for too much in the selection process for directors. This interviewee added that the situation was due to a "political culture" that has existed in Catalonia and more generally throughout Spain since the Spanish transition. However, some public managers stated that there had been a shift away from the importance of political loyalty to another kind of loyalty more in line with professional needs. Professional loyalty complements political affinity while also valuing managerial capacity.

Regarding the discretional sphere, significant divergence in opinions was found. Some public managers claimed that the discretional sphere-the autonomy or the capacity to make decisions - does not exist. In fact, one of them categorized it as a "real drama" meaning that this sphere was not developed at all although it was highly needed. However, there is also another side that acknowledges that public managers have a high degree of managerial freedom, not only when defining strategic objectives and accomplishment indicators but also on the operational side, where budgets and human resources are concerned, "even if this is always framed by our legal framework," as one of manager put it.

At one extreme, one interviewee claimed that managers were trapped by the strictness of human resources management and the absence of a strategic vision by the 
institutions' political leadership. Similarly, another summarized his opinion as: "In this area, managers just sign contracts and pay salaries."

At the other extreme, some think that the inflexibility that is sometimes present in managerial actions can be overcome by "seeking the limits of the law" to emphasize that managerial actions sometimes push the boundary of legal activities. "Here what you propose is what it gets done," said another, going on to explain that managers are responsible for "bringing the projects to the table," considering all the political intentions that affect them. Another respondent said that the manager is always exposed to political influence or interference. "Many times the manager hides himself behind the rigidity of human resources policy in order to avoid managing, and this is precisely the challenge for managerial actions," he concluded.

"Managers can influence the definition of the strategic objectives of their organizations," stated one public manager, adding: "It is logical that political interference appears in the manager's tasks. This is not the problem. The problem is the degree of politicization or the level of interference that we must have. Ten percent is acceptable. Or perhaps managers do not take on roles that require political competence? This is often the case."

\section{PPM development according to the administration domain}

According to the viewpoints of the managers sampled the degree of PPM development perceived by managers working in local administrations (direct local government) is higher than that of managers working in autonomous administration (direct autonomous government). In addition, the average degree of PPM development for directors of decentralized organizations in the local sphere (indirect local government) is higher than that of their counterparts working in indirect autonomous government. 
When managers where asked if they believe that local administration had higher levels of PPM development than autonomous administration, half the sample answered that they "completely agreed" with this statement, 30\% answered that they partially supported the statement and the last $20 \%$ did not agree with it.

Among those who agree with the hypothesis that local public organizations have more developed PPM than autonomous public organizations, there is also agreement about the reasons. In councils, public managers must have a well-developed professional profile and a significant degree of managerial freedom to be able to deal successfully with the everyday demands of the population, since these tasks are very close to local public managers: they must therefore pay more attention to their managerial acts.

The data concerning managers in intermediate positions show that they partly agree that local administrations have more developed PPM, although their opinions vary. Other participants also suggest that there is a lack of homogeneity among the Catalan councils. For instance, another manager asserted that he did not support the statement, mainly because "Barcelona is one thing and the rest of the Catalonian councils are another."

Directors who did not agree with the statement suggested some interesting reasons why. One said that while examples of PPM could be found at local level, they were short-lived, lasting only for the period that the mayor promoting the initiative was in charge of the municipality. He also argued that these experiences had not been extended to the majority of councils, emphasizing a complete lack of PPM development in small municipalities, and stressing that they could not be compared to big ones.

In the same interview, this director said that in Catalonia there were "just 13 municipalities with more than 70,000 citizens, and because of that it is not true that only 
the municipality of Barcelona is making efforts to develop PPM." In fact he went further, presuming that "even those councils that are in between 10,000 and 70,000 citizens have made efforts to develop a more managerial oriented public administration." However, he doubted their likelihood of success.

Another manager said that, according to his point of view, the question of the institutionalization of PPM in Catalonia could not be tackled without addressing the main problems of the Catalan and the Spanish governments: the relations between labour forces and administrations over reform of the public sector. Another manager questioned whether "it makes any sense to adopt PPM when the managerial functions of human resources that correspond to the traditional development of public administrations have not been achieved yet? Public servants, with all their features and privileges, as well as the labour forces, are the biggest enemies of the institutionalization of PPM.”

In favor of the opinion that the government of Catalonia has a higher degree of professional management, in contrast to local governments where managers are more exposed to political pressures, one interviewee stated: 'in local government, managerial actions are more subject to the wishes of the politicians in charge of the council."” Another added: "In the autonomic regions greater efforts have been made for the development of PPM."

Managers were also questioned about the extent to which they agreed with the following statement: "There is a higher degree of PPM development in decentralized administrations than in centralized ones." Ninety percent of our sample responded that they "completely agreed" with this statement. The other $10 \%$ of respondents fall into two groups: 5\% said that they partially supported the statement, and the others responded that they did not agree at all with it. 
Moreover, during the focus groups, managers elaborate on a subset of arguments representing some of the benefits of having PPM in decentralized administrations. We have summarized their thoughts as follows:

a) To have agencies with discretional spheres that allow public managers to make decisions with more freedom, and fewer restrictions, than direct public management organizations.

b) "To be out of the political noise span," as one of the managers put it.

c) To be oriented toward criteria of competitiveness and market logics.

d) "To be the captain of a smaller boat," as one interviewee concluded.

One could argue that these benefits should also be applied to centralized administrations. However, it was noted that the public enterprise model (representing decentralized organizations), is not applicable to all areas of autonomous government. For example, the security department cannot be decentralized for obvious reasons, although some exceptions can be found (see Ortiz, 2010). In this sense, managers share the common view that public administrations must be careful not to catch "agency fever," as Pollitt, et al. (2001) have warned.

\section{Conclusions}

A first insight is that two particular areas require most attention in the Catalan government. The first is the accountability system, an articulated procedures system based on performance assessment. The second is the incentives system, a constellation of incentives (positive and negative) that contribute to the creation of a public management environment that produces permanent innovation and positive outcomes. Thus, the first concluding remark that we suggest after our analysis is that efforts should be made to develop performance management frameworks based on both ex ante 
performance measurements and ex ante performance management (Broadbent and Laughlin, 2009).

It has been argued that implementing these measures might lead to higher levels of bureaucratization in public administrations. However, it is important to distinguish between regulation and bureaucracy. As Hood et al. (1998) argue, the development of regulatory strategies is necessary for the development of public management reforms. However, PPM should also consider past critiques of managerial reforms within the public sector (for a review, see Diefenbach 2009). In this sense, we emphasise the second concluding remark of this article: despite the last managerial reforms that have shaped several public administrations, effort is still required to improve the management capacity of public managers. Moreover, we highlight that this effort should be translated in having well developed accountability and incentive systems, together with an adequate functional field and discretional sphere.

The third conclusion of this study is that, with the exception of some isolated cases in the local sector or in decentralized agencies, Catalonia still lacks incentives systems devoted to the managerial activities of its public administrations. One public manager we interviewed argued that a results-based culture must be implemented in public administrations. Incentive systems seem to be still hard to find in most public administrations, however, as Longo (2006) posits, they represent a fundamental requisite to enhance the performance of public organizations.

Finally, a key element of PPM is developing the capacity to distinguish between politics and management in public administrations (see, for example, the German experience, described in Adam and Behm, 2006). As Gray and Jenkins (1995) propose, politics and management need not be divided entirely, but boundaries can nonetheless be set to ensure that both logics can coexist successfully, as they must inevitably do. In 
the line of the managerial reforms that most western public administrations are developing, the experience presented in this article highlights several policy implications for those countries where there is still not enough distinction between public managers and politicians. For instance, a practical example on these effects is provided by Gallego and Barzelay (2010) in their case study of Spain, highlighting the strong influences of politics in public management. Arguably, the existing politization of the Catalan government may act as a potential determinant of the lack of performance evaluations in public organizations. As our interviews have shown, most public managers are still recruited and evaluated based on their political loyalties; because of that, acting in the same line that the political party in charge becomes fundamental for public managers. This culture of politization, thus, represents a serious issue when designing a performance evaluation on public managers. Because of that, our fourth conclusion is that before performance evaluations or incentives can be effectively put in place, the culture of politicization around management positions should be curbed in Catalonia.

In this sense, the framework presented can be used as a reference to evaluate the degree of PPM development within each country. After a first evaluation phase, policymakers will be then able to set policies that can enhance the institutionalization of the role of public managers; whether this is focused on an accountability and incentive system -such as in the case of the Catalan Government-, or in the functional field or the discretional sphere, will rely on the characteristics of each government. 


\section{Acknowledgements}

This paper reports work undertaken by the authors as part of MICINN Research Award CSO2009/11351, and AGAUR Research Award SGR1483. We would like to thank Rhys Andrews, Andrew Massey and the two anonymous reviewers for their helpful suggestions. We also thank the research assistance of Marina Pol and Héctor Arámbula.

\section{References}

Adam, B. and Behm, C. (2006), The Use of Budget Reforms to Modernize Governance in German Local Government. Public Money \& Management, 26, 4, pp. 217220.

Aucoin, P. (1990), Administrative Reform in Public Management: Paradigms, Principles, Paradoxes and Pedulums. Governance, 3, 2, pp. 115-137.

Bardach, E. (1998), Getting Agencies to Work Together. The Practice and Theory of Managerial Craftmanship (Brookings Institution Press, Washington DC).

Barzelay, M. (2000), The New Public Management: Improving Research and Policy Dialogue (University of California Press, Berkeley).

Barzelay, M. (1999), How to Argue about the New Public Management.International Public Management Journal, 2, 2, pp. 183-216.

Barzelay, M. and Gallego, R. (2010), The Comparative Historical Analysis of Public Management Policy Cycles in France, Italy, and Spain: Symposium Introduction. Governance, 23, 2, pp. 209-223.

Barzelay, M., \& Thompson, F. (2010). Back to the Future: Making Public Administration a Design Science. Public Administration Review, 70, Issue Suplement s1, pp. 295-297. 
Bresser-Pereira, L. C. (2004), Brazil's Quasi-Stagnation and the Growth Cum Foreign Savings Strategy. International Journal of Political Economy, 32, 4, pp. 76-102.

Broadbent, J. and Laughlin, R. (2009), Performance Management Systems: A Conceptual Model. Management Accounting Research, 20, 4, pp. 283-295.

Broadbent, J. and Laughlin, R. (1997), Evaluating the 'New Public Management' Reforms in the UK: A Constitutional Possibility? Public Administration, 75, 3, pp. 487-507.

Diefenbach, T. (2009), New Public Management in Public Sector Organizations: The Dark Sides of Managerialistic "Enlightenment". Public Administration, 87, 4, pp. 892-909.

Dilulio, J. (1994), The Promises of Performance Measurement (pp. 94-102). Working Paper: Brookings Institution, Center for Public Management.

Dunleavy, P. and Hood, C. (1994), From Old Public Administration to New Public Management. Public Money \& Management, 14, 3, pp. 9-16.

Fern, E. F. (2001), Advanced Focus Group Research (Sage, Thousand Oaks).

Frey, J. H. and Fontana, A. (1991), The Group Interview in Social Research. Social Science Journal, 28, 2, pp. 175-188.

Gallego, R. and Barzelay, M. (2010), Public Management Policymaking in Spain: The Politics of Legislative Reform of Administrative Structures, 1991-1997. Governance, 23, 2, pp. 277-296.

Gray, A. and Hood, C. (2007), Public Management by Numbers. Public Money \& Management, 27, 2, pp. 89-89.

Gray, A. and Jenkins, B. (1995), From Public Administration to Public Managment: Reassessing a Revolution? Public Administration, 73, 1, pp. 75-99. 
Hesse-Bibber, S. N. and Levy, P. (2006), The Practice of Qualitative Research (Sage, Thousand Oaks).

Hood, C. (1991), A Public Management for all Seasons? Public Administration, 69, 1, 3-19.

Hood, C., James, O., Jones, G., Scott, C. and Travers, T. (1998), Regulation Inside Government: Where New Public Management Meets the Audit Explosion. Public Money \& Management, 18, 2, pp. 61-68.

Longo, F. (2004), Mérito y Flexibilidad. (Paidós, Barcelona).

Longo, F. (2006), Oferta y demanda de gerentes públicos. Un marco de análisis de la institucionalización de la dirección pública profesional. Reforma y democracia. Revista del CLAD, 35, pp. 63-95.

Meier, K. J. and O'Toole, J. L. J. (2009), The Proverbs of New Public Management: Lessons From an Evidence-Based Research Agenda. American Review of Public Administration, 39, 1, pp. 4-22.

Morgan, D. L. (1993), Successful Focus Group: Advancing the State of the Art. (Sage, Newbury Park).

Morgan, D. L. (1996), Focus Group. Annual Review of Sociology, 22, 1, pp. 129-152.

OECD. (2005), Annual Report (OECD, Paris).

Ortiz, C. (2010), The New Public Management of Security: The Contracting and Managerial State and the Private Military Industry. Public Money \& Management, 30, 1, pp. 35-41.

Pollit, C., Bathgate, K., Caulfield, J., Smullen, A. and Talbot, C. (2001), Agency Fever? Analysis of an International Policy Fashion. Journal of Comparative Policy Analysis: Research and Practice, 3, 3, pp. 271-290. 
Pollit, C. and Bouckaert, G. (2000), Public Management Reform: A Comparative Analysis (Oxford University Press, Oxford).

Sprigings, N. (2002), Delivering Public Services Under the New Public Management: The Case of Public Housing. Public Money \& Management, 22, 4, pp. 11-17. 